\title{
LESSONS LEARNED FROM THE IMPLEMENTATION AND ASSESSMENT OF STUDENT-CENTERED METHODOLOGIES
}

\author{
Maria T. Oliver-Hoyo \\ North Carolina State University, Chemistry Department \\ Raleigh, NC USA \\ maria_oliver@ncsu.edu
}

\begin{abstract}
The $\mathrm{CAcL}_{2}$ approach (concept Advancement through chemistry Lab-Lecture) incorporates three major educational methodologies into one: a student-centered approach, the full integration of lecture and laboratory formats, and hands-on activity based-instruction. This format has been tested for cognitive and attitudinal gains in students and the results clearly point out to its benefits. Instructional materials for a oneyear general chemistry sequence have been developed to facilitate its implementation in classrooms. The most important aspects of the format with tested practices are discussed while challenges and implications of findings are shared in order to assist instructors interested in implementing innovative formats of instruction such this one, the $\mathrm{CAcL}_{2}$.
\end{abstract}

Keywords - Educational innovation, student-centered methodologies, educational assessment

\section{INTRODUCTION}

Globally, academic institutions of higher education evaluate faculty efforts in three realms; teaching, research, and service. However, even though academic environments are expected to embrace best practices in teaching and educational research, the inertia to actually implement significant changes is often times palpable [1-2]. For example, during the early part of the $20^{\text {th }}$ century in the United States, the general chemistry curriculum only saw changes in course content since simple adjustments of topics was easily accepted and put into practice [3-4]. In spite of the growing amount of educational research that emphasizes the importance and impact of educational methodologies in the attainment of students' learning, content remains the main focus of faculty efforts towards teaching. The project described within evolved from the author's firm belief that in order to achieve effective instruction, which translates as instruction that attains students' learning, content is only as good as its "engaging power". The hurdles and progress of our implementation will be shared in hopes that others learn from our experience. The assessment of our efforts might convince others of the feasibility and merits of this approach.

The $\mathrm{CAcL}_{2}$ approach (concept Advancement through chemistry Lab-Lecture) incorporates three major educational methodologies into one: a student-centered approach, the integration of lecture and laboratory formats, and hands-on activity based-instruction. Independently these methodologies have been tested and shown to be highly effective in small groups of students, primarily in groups below 25 students [5-8]. The $\mathrm{CAcL}_{2}$ approach implements these methodologies in large enrollment groups of ninety-nine students. This approach emulates the principles and philosophy of the SCALE-UP format ("Śtudent-Centered Active Learning Environment for Undergraduate Programs") whose merits include the attainment of better conceptual understanding by students [9-11]. The $\mathrm{CACL}_{2}$ approach is the chemistry specific response to the SCALE-UP format.

\section{METHODOLOGIES INCORPORATED INTO THE CACL $\mathrm{C}_{2}$ APPROACH}

Our implementation of a student-centered approach mainly entails a shift from the teacher as the provider of content to the teacher as the facilitator of learning. This approach changes the focus from what the teachers do 
to convey information to how the teachers assist students in achieving educational goals and objectives. Lea et al. investigated student-centered learning and discussed the main principles we follow in the $\mathrm{CAcL}_{2}$ approach [12]. These can be summarized in one sentence: an interdependence between teacher and student that promotes an increased student's sense of autonomy and accountability and demands responsibility for reflection on the learning process by both. In the classroom, this is portrayed as a lively environment where students are primarily "doing" something while the teacher attends to students questions. Outside the classroom this demands deep reflection from students on the learning objectives of each activity and from teachers on how well these learning objectives were accomplished. A challenge for teachers that use more traditional approaches is to transform "lecture" material into activities where students are able to explore and ponder rather than accept facts and information. The biggest challenge in chemistry instruction is to dethrone the belief that students learn best by listening to the accounts of knowledgeable instructors.

It is widely accepted that the laboratory is an integral component of experimental science courses. The effectiveness of the laboratory depends on a considerable number of factors ranging from the defined goals and available instructional resources to the behavioral patterns of participants [13]. However, for decades, students have reported laboratory work as very effective in promoting their interest [14]. Considering the positive interdependence between cognitive and affective variables, we deemed crucial the integration of the laboratory component into the classroom environment. In practice, this is attained by either modifying laboratory experiments so that they can be performed "in-time" in the classroom environment or by having access to laboratory facilities so that experiments can be performed concurrently as the topic is discussed in the classroom. This departs from doing experiments in a concerted fashion to using the laboratory as an integral resource in the advancement of conceptual understanding. It is expected that the lab component follows an inquiry-guided approach rather than a verification one. Procedures are written so that the students generate questions themselves rather than verify expected results. In turn, this evokes the principles of a student-centered approach.

For us, activity-based instruction was then the logical extension of the first two methodologies. Our operational definition of activity-based instruction is synonymous to "hands-on, minds-on" learning where physical materials and mental thoughts are required to find meaning and pursue understanding. Activities may come in a variety of forms including actual experimentation and gathering of data, studying a simulation or animation, solving written problems, discussing an article or results, data mining the Internet, etc. Regardless of the form that the activity takes, the crucial aspect is to engage the mind in an inquisitive way. For example, if the activity involves a demonstration performed by the instructor, students could be asked to document or report on their observations, give a plausible explanation, answer questions on a worksheet, propose changes to the demonstration and predict what will happen, etc. Any "passive" experience can be transformed into an "active" one where engagement of the mind is intentionally evoked.

\section{DESCRIPTION OF THE $\mathrm{CACL}_{2}$ APPROACH}

The main aspects for the implementation of the $\mathrm{CAcL}_{2}$ approach can be categorized into a) facilities and classroom design, b) classroom management techniques and dynamics, and c) development of curricular materials. Different universities that have adopted the SCALE-UP format have implemented different facilities designs [15]. The primary aspect to consider is that the classroom setting should facilitate communication among students and between students and instructors. In our case, we have classrooms fitted with round tables of nine students or rectangular tables forming a " $U$ " accommodating 6 students per table. In the first case, the room holds 11 tables for a total of 99 students and the second setting holds 48 to 70 students. Multiple projectors allow instructional material to be displayed from an instruction station to multiple screens while white boards surrounding the room are prominent in these classrooms so that the participants have access to expression mediums that can be seen by everyone. Answers written on the whiteboards allow instructors to quickly scan and easily assess comprehension and/or consensus. The key elements for a feasible classroom design are accessibility of resources and communication among students and instructor. Technology enhances this environment so we provide laptops with Internet access for every group of students. Fig. 1 includes a picture of our 99-student facility and a smaller SCALE-UP room at the Universidad Politécnica de Madrid with the same configuration. 


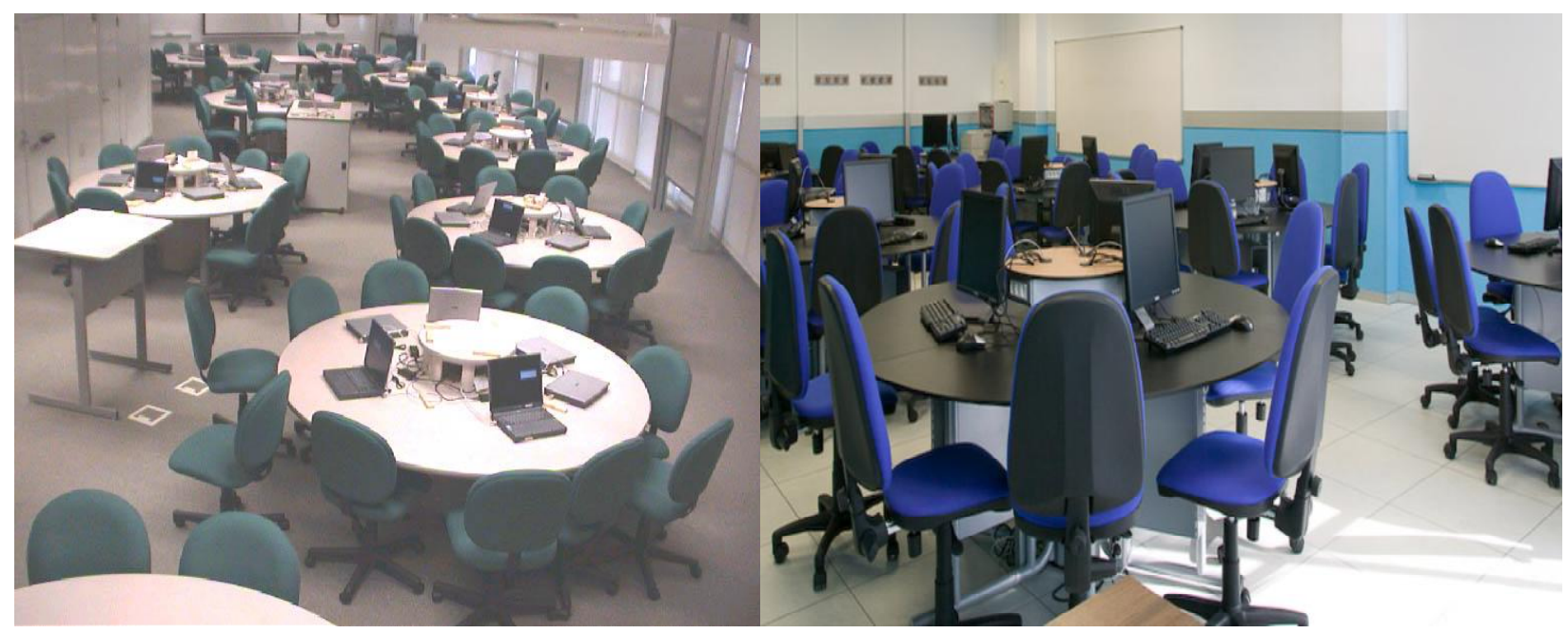

Fig.1. SCALE-UP rooms at North Carolina State University (U.S.A.) and Universidad Politécnica de Madrid, Spain

Classroom management techniques are especially important with large groups. In order to manage an active class of up to 99 students in an effective manner, we start by promoting a sense of community where all students have name cards placed in front of them to help both instructors and students to communicate in a more personal fashion. All tables are numbered to facilitate distribution and collection of materials. Computers are used in five major areas: class management, electronic homework, data collection, graphical analysis, and simulations and animations. All class materials including a daily class agenda are provided using software designed for the organization, management, and distribution of curricular materials.

Even though electronic homework is due every class period, additional handwritten assignments keep students on task especially during the class period. Non-electronic homework is collected on a regular basis, however grading of 99 papers every class period can be a haunting task for instructors. To solve this issue we employ simple strategies that make every student responsible for the assignment but only a handful of papers graded at any given time. For example, in the room with 11 tables a 12-sided die is rolled and the "lucky" number is the table that will hand in the assigned work. The instructor may roll the die again for a total of 18 papers to grade. Another simple strategy involves having all students' names in a box and the instructor calling on a few names at a time. For these strategies to work it is critical that all graded assignments must count towards the final score in the course. The percentage will depend on the instructor and the course, however, even a small percentage, $\sim 2-3 \%$, will grab students' attention and make these assignments important in the eyes of the students. Since "luck" is unpredictable, students soon start to recognize that if their name is called only once during the semester, that one assignment will count 2-3\% towards the final grade. This conveys the message that every assignment is as important as the last one or as the next one to come.

Intrinsic to the methodologies blended in the $\mathrm{CACL}_{2}$ approach is a highly collaborative environment. The benefits of cooperative grouping are well documented [16-19] and research on collaborative groups in SCALEUP physics classes has indicated optimal conditions when students form groups of three which in turn are part of a bigger group such as the full table [20]. We have closely monitored grouping arrangements and assessed for effectiveness using peer evaluations and test grades. For example, in order to promote the collaborative effort, bonus points have been added to individual exam scores when the average team grade is above a specified minimum on an exam. This seems to encourage advanced students to help group members who may be struggling with the material. At the same time, slower students tend to show a deeper sense of responsibility. In other instances, the instructor has formed the groups to ensure heterogeneous abilities among group members and comparable groups across the room [21]. Our experience in the $\mathrm{CACL}_{2}$ format is that either a loosely structured or a highly structured collaborative approach benefits students. Collaborative work also helps in promoting soft skills such as communication and teamwork.

The development of the curricular materials is based on activity-based instruction where chemical handling, micro scale techniques, and technology are seriously considered. The activities developed for the one-year general chemistry sequence course are readily available to download at no cost to instructors [22]. These activities took into account the existing research on chemistry misconceptions [23] where misconceptions on a 
particular topic are explicitly stated in each activity so that instructors may monitor student learning as the activity progresses. Every activity developed has been written in a specific format in order to guide instructors as facilitators of class work. An outline of a blank activity form and explanation of components is provided in Fig. 2. We took different resources such as demonstrations, experiments, and even traditional problems and modified them to use these resources in a hands-on, minds-on approach. For example, demonstrations once performed by the instructor have been modified so that students can perform them and work on the accompanying instructional materials in a self-directed manner. If the demonstration needs to be carried out by the instructor then worksheets are used to guide student learning and keep them mentally engaged in observing and explaining the chemical phenomena being demonstrated. The major modification to the existing laboratory experiments included re-writing procedures and changing them from a verification or "cookbook" lab to a more inquiry-guided approach. The generation of meaningful questions by students can't be underestimated with regards to its benefits in advancing understanding.

\section{TITLE}

Time: time suggested for completing activity

Topic: topics covered by activity

Type: probe or investigation

Level: introductory, intermediate, or advanced

Overview: statement outlining the activity

Materials and Equipment: items needed to complete the activity

Objective(s): statements identifying the intended learning outcomes

Misconceptions: misunderstandings that conflict with scientific theory

Other Student Difficulties: areas that should be given special attention

Prerequisites: concepts or material needed to complete the activity

Activity Table outlines every step of the activity for instructors

\begin{tabular}{|l|l|l|}
\hline \multicolumn{1}{|c|}{ Task } & \multicolumn{1}{|c|}{ Reason } & \multicolumn{1}{|c|}{ Notes } \\
\hline $\begin{array}{l}\text { Action to be taken by students or } \\
\text { instructors }\end{array}$ & $\begin{array}{l}\text { Why the action is is } \\
\text { important }\end{array}$ & $\begin{array}{l}\text { Helpful information for } \\
\text { instructors }\end{array}$ \\
\hline
\end{tabular}

Related Activities: activities that incorporate related concepts

References: the resources used in developing the activity

Supplementary Material: Discussion of concepts, explanation of demos and procedures

Fig.2. Activity template depicting information contained in every activity

\section{ASSESSMENT EFFORTS}

Studies involving the $\mathrm{CACL}_{2}$ approach tackled both cognitive gains and attitudinal aspects. One study concentrated on the use of higher-order cognitive skills [10] while two studies looked into the intricacies of students' attitudes towards learning in this new format [24-25]. We were able to show that students in the 
$\mathrm{CACL}_{2}$ format outperformed students in a traditional lecture setting in three out of four examinations with only the third examination showing no significant differences between the two groups. The analysis for each exam compared a subset of questions carefully chosen and constructed to satisfy the use of higher-order skills (specifically application, analysis, synthesis, and evaluation). Two classes participated in this study where one was conducted in a traditional lecture format and the other in the $\mathrm{CAcL}_{2}$ approach. As many factors as possible were controlled for the two classes including; same instructor taught both classes, both classes met during midafternoon hours of the day, comparison groups were equivalent in terms of demographics, ethnicity, and gender, contact hours between instructor and students were closely monitored to keep them comparable, same syllabus and content coverage, and strict monitoring of time on task. Attention to details was a priority during the planning and scheduling of this study. For example, exams were given to both classes one week after coverage of material in class and the same teaching assistant graded a specific set of questions for both classes. To verify grading uniformity, a second grader reviewed all identical scores.

The data were analyzed using a three-way ANOVA model to answer the question whether the instructional method affected overall student performance. ANOVA allowed us to take into account other sources of variation besides the instructional method such as student major, exam, and any two- and three-way interactions when testing for the class effect. The analysis considered adjusted exam scores for each student where these scores were calculated using only the percentage of points earned in the identical questions for each exam. Class, major, and exam were considered the major sources of variation in student overall performance. This study complied with the requisites of exam scores across individuals and within individuals been statistically independent, students representing a random sample, and only complete sets of data included in the analysis.

A second study looked into the attitudes of the students enrolled in these two classes [25]. The importance of attitudes towards science comes from the widely accepted assumptions that achievement and attitude are positively interdependent [26] and that affective variables are as important as cognitive ones in molding students' learning [27]. Two instruments were used as foundation for the pre- and post-surveys administered electronically to the students during the first and last two weeks of classes. Our survey contained questions from the Derived Chemistry Anxiety Rating Scale [28] and the attitudinal test developed at Grinnell College and University of California at Berkeley [29]. Students chose the option that best matched their feelings on a Likert scale from 1 to 5 . Questions addressed attitudes toward learning science in general (14 questions) and chemistry anxiety in learning the subject, being evaluated in chemistry courses, and handling of chemicals ( 25 questions).

No one will contest the fact that instructors are an important source of variation and can dramatically influence student performance and attitudes in the classroom [30-31] so the first step was to make sure that each audience did not perceive the instructor differently. Departmental evaluations were used toward this purpose and analysis of these student evaluations showed there was no significantly different perception of the instructor in the two classes.

Once this was shown, scores from the pre-test and post-tests were analyzed. Due to the complexity of factors involved in attitudinal responses, the use of raw data (comparing directly pre-test with post-test results) raised validity concerns. Therefore, we used residualized gain scores, RGS, which tend to attenuate some of the difficulties associated with comparing raw scores. The RGS analysis demonstrated that $77.1 \%$ of the student population in the $\mathrm{CAcL}_{2}$ class reflected positive gains above the control section (traditional format). This translates into an overwhelming majority of students in the $\mathrm{CACL}_{2}$ class with positive attitudes above those expressed by students enrolled in the traditional class.

A third study looked into students' perceptions toward three elements of the $\mathrm{CACL}_{2}$ format: the hands-on activities, graphical analysis assignments, and collaborative aspects of the class [24]. Three methods for data collection were used that included interviews, journal entries, and surveys. Triangulation of these attitudinal aspects by these three different methods showed convergence only for the most objective construct, the graphical analysis. When convergence is achieved, greater validity exists in the conclusions drawn [32] as was the case with the attitudes of students toward their ability to construct and interpret graphs. Interviews and journal entries regarding attitudes toward cooperative grouping and hands-on activities agreed and results suggest that student attitudes became more positive as the semester progressed. Surveys did not elucidate why students felt the way they did and in fact conflicted with the results from the other two data collection methods. The fact that surveys was the most unreliable of the three methods of data collection came as a surprise to us since surveys are the most common qualitative method used in a variety of assessments [33]. 
These three studies offer a well-rounded approach towards assessment of this format. Quantitative and qualitative data pointed to the success of this format with respect to cognitive and attitudinal gains in students when compared to a traditional format of instruction.

\section{CHALLENGES}

The best scenario for the success of this kind of initiative is that where both faculty and institutional administration are committed to the change. Even in this scenario, both parties will face some challenges. Since institutional challenges are very specific to each particular administration, these will not be addressed here. The major individual challenge faculty confronts is believing on the educational research that points to the effectiveness of these strategies in promoting students' learning. Teachers teach the way they were taught, therefore a format that departs from this experience requires a fundamental conviction of its need and its benefits. This may be attained by different mechanisms: a) the instructor gets educated in the educational research literature and genuinely wants to test such results in his/her classroom, b) the instructor is exposed to a colleague that can model the practice and show effects of such an implementation, c) the instructor gets frustrated with his/her inability to get specific results in his/her classrooms and wants to do something about it, and d) the instructor gets directives from institutional administration that changes must occur. The most promising of these scenarios are those where the instructor is inspired to change.

Once the instructor is convinced that active learning is actually a more promising approach to accomplish the teaching/learning objectives than passive lecturing, then the inertia of changing instructional ways comes into play. For the new instructor the same amount of time that is required to prepare a traditional lecture could be spent preparing an active class but for the seasoned instructor changing to a new format demands time they might not be willing to invest in an "already prepared" course. Being aware of the existence of appropriate curricular materials aids immensely in reducing the amount of time an instructor might have to spend preparing for a particular course. Professional development seminars, journal publications, and chemical education conferences are only three examples of forums where these resources are disseminated.

Commitment to action generates further questions and the most common one is how to cover the same amount of content in an active-learning environment. This is a legitimate concern but totally unfounded. If the instructor plans to lecture and then add activity-based instruction on top of that, then the amount on task will definitely increase. If the instructor understands that now the teaching is transformed into a different format where the activities replace the lecturing, then the time on task for the students in the classroom remains the same. This goes back to the personal conviction that the instructor does not need to tell everything but must let students figure out answers on their own and formulate questions from their struggles during the learning process. This is a radical change and the best way to become efficient at it is to take it one step at a time. For example, our incorporation of activity-based instruction was a slow process where only three activities were incorporated during the first semester of the new approach. Subsequent semesters built on previous experiences and from three activities we escalated to six, ten, 14 (one activity per week), etc. up to where we currently do an average of two activities per class and minimize the lecture to 15 minutes every class period. The same applies to every new aspect of a new approach whether it is introducing collaborative learning techniques or incorporating technological resources. The instructor must adopt a limited number of innovations until he/she feels comfortable enough and can handle incorporating new ones. It is important that the instructor gives each particular innovation a chance to succeed and this can only be accomplished when the innovation remains in effect for at least the duration of one semester and is tried in a consistent manner. 

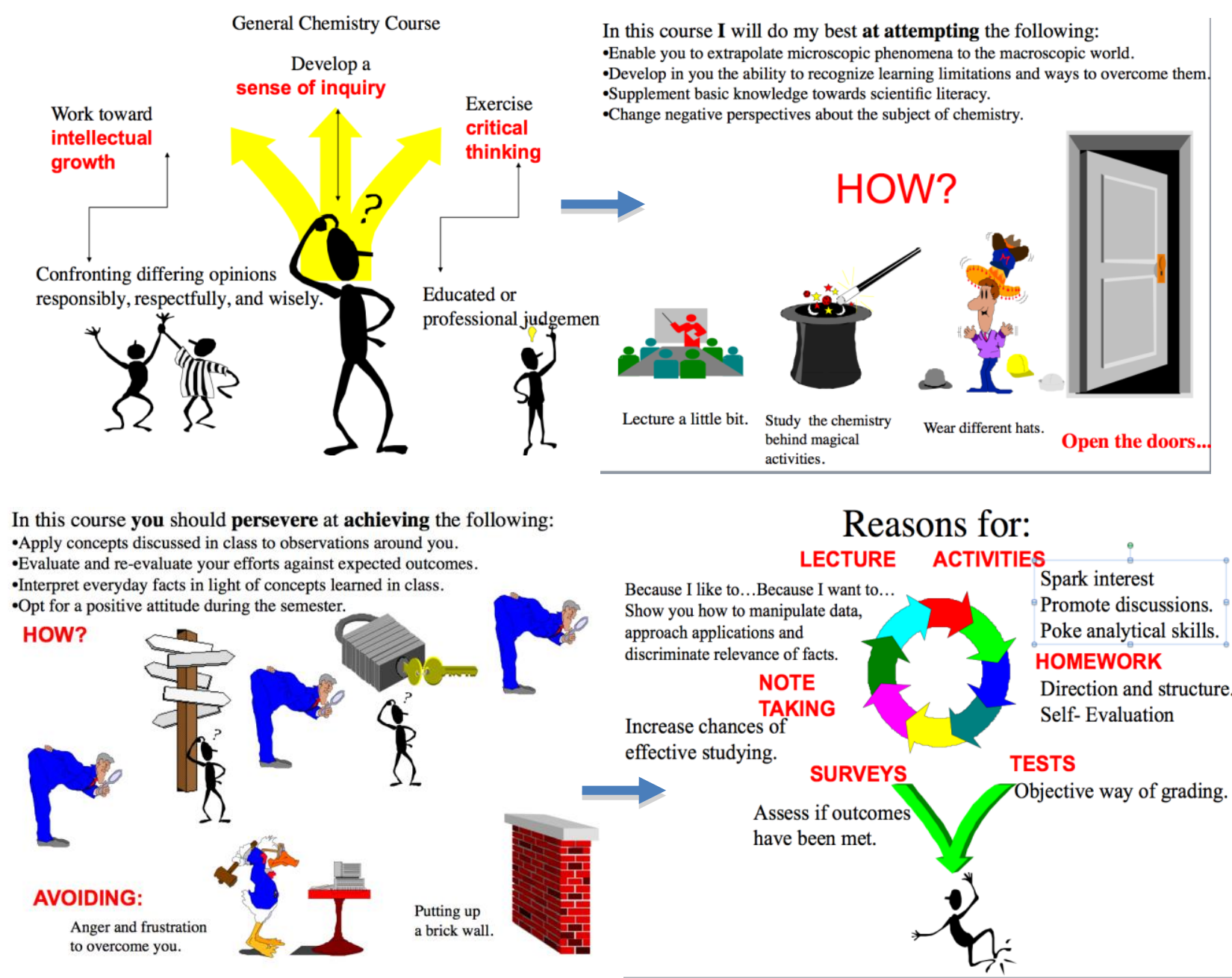

Fig.3. Sequence of slides used to discuss the class format.

Another potential challenge every pioneer instructor faces is the lack of buy-in from the students themselves. Instructors must be aware that approaches where students are more responsible for their own learning receive lower rankings on student evaluations [34] especially if there is no critical mass of students been taught with the innovative approach. Our experience reflects that the students involved in our studies started the semester with strong apathy towards the new format but by the end of the semester realized the benefits the format brought to their learning [25]. Just like instructors, students are used to passive lecturing and if the outcomes do not meet their expectations it is very easy to blame it on the format rather than reflecting on how to embrace the innovation for better learning. Instructors may work by consistently reminding students how the process works and what are the expectations. A little bit of humor might help as shown in Fig. 3. The author discusses these slides the very first day of classes to set the tone for the new approach and uses them a couple of times during the semester.

\section{IMPLICATIONS}

Embedded throughout this manuscript is a dense thread of issues that can be overwhelming to absorb all at once. Constantly making a mental note that changes can happen one step at a time should help. For the individual instructor that is isolated and embraces innovation because of a personal interest, the suggestions given here should be sufficient. At the institutional scale, changes may develop from the bottom up (faculty generated) or the top down (administration enforced) but neither channel will produce fruitful outcomes unless there is a core of people genuinely interested, seriously committed, and strongly prepared to make changes and confront obstacles. For the instructor that wants changes reflected at a larger scale beyond his/her own classroom then other qualities must be invoked such as patience, perseverance, and flexibility. 
Faculty tend to be more receptive when a colleague speaks from experience so setting the example, modeling new approaches, and candidly discussing results with colleagues may work wonders towards adoption of these practices.

What works in one environment at a particular institution or within a specific discipline might not work at another so the need to provide alternative options is of primary importance. For example, the $\mathrm{CACL}_{2}$ approach is based on the SCALE-UP format originally developed for physics. The physics SCALE-UP facilities are not properly equipped to handle the "wet" nature of chemistry in terms of hoods or gas lines. Therefore, the activities performed in the physics SCALE-UP classroom had to take into account the nature of the reagents and use of micro scale techniques. A second alternative involved conducting the activities in the lab setting concurrently with the "lecture" portion as previously discussed. This flexibility is key to success and it should be considered without loosing perspective of what this format is all about: engaging students in an active, inquirybased environment. Whatever needs to be modified to accomplish "a student-centered approach, integrating lecture and laboratory formats, and hands-on activity based-instruction" is a step in the right direction.

Any educational reform should include formative evaluations to assess what should be modified and what should be further advanced. This process may promote scholarly work in teaching as the implementations are evaluated and the results are disseminated. Teaching as a scholarly endeavor requires that what we do in the classroom is raised to the highest level of intellectual activity. Thinking about teaching starts where all intellectual inquiry begins: questions about what is going to happen, how to explain what happens, and how to support and replicate the findings. This is a reflective, systematic, replicable, and public process where exposure to critical review and evaluation is fundamental to the process. Faculty taking this endeavor has the potential to raise it to scholarly work.

\section{CONCLUDING REMARKS}

The development, implementation, and assessment of the $\mathrm{CACL}_{2}$ approach have been a process that is still evolving as faculty, conditions, and resources continuously change both within and among institutions. Some aspects of this format have been well thought out and replicated such as the classroom management techniques while others have been thoroughly modified as evidenced by the variety in SCALE-UP facilities at different institutions. Still certain aspects may further benefit from modifications and assessments especially when newly implemented. Even the characteristics of the students' population ("class personality") may dramatically change each semester compelling instructors to adjust. While chemical reactions and physical phenomena may be carefully controlled, there is no such advantage available in our classrooms. The dynamic nature of educational initiatives is probably one of its most exciting features as new challenges, new questions, and new avenues need to be explored for effective instruction to take place in our classrooms.

\section{REFERENCES}

1. L. H. Rickard, Reforms in the General Chemistry Curriculum, Journal of Chemical Education, 69(3), 1992, pp 175-177

2. M. Cooper, The Case for Reform of the Undergraduate General Chemistry Curriculum, Journal of Chemical Education, 87(3), 2010, pp 231-232.

3. J.N. Spencer, Refocusing the General Chemistry Curriculum: General Chemistry Course Content, Journal of Chemical Education, 69(3), 1992, pp 182-186.

4. B.W. Lloyd, A Review of Curricular Changes in the General Chemistry Course during the Twentieth Century, Journal of Chemical Education, 69(8), 1992, pp 633-636.

5. R. W. Ricci and M. A. Diizler, Discovery Chemistry: A Laboratory-Centered Approach to Teaching General Chemistry Journal of Chemical Education, 68(3), 1991, pp 228-231. 
6. L. B. Flick, The meanings of hands-on instruction, Journal of Science Teacher Education, 4(1), 1993, pp 1-8.

7. R. S. Moog and J. N. Spencer, Process Oriented Guided Inquiry Learning (POGIL), Chapter 1 in ACS Symposium Series, 994, 2008, pp 1-13.

8. L. B. Bruck, A. D. Bruck and A. J. Phelps, "Gone" into Solution: Assessing the Effect of Hands-On Activity on Students' Comprehension of Solubility, Journal of Chemical Education, 87(1), 2010, pp 107-112.

9. R. Beichner, The Scale-UP Project: A Student-Centered, Active Learning Environment for Undergraduate Programs, National Academy of Sciences, September 2008, URL: http://www7.nationalacademies.org/bose/Beichner_CommissionedPaper.pdf, Accessed March 152010.

10. M. Oliver-Hoyo and D. Allen, Effects of an Active Environment: Teaching Innovations at as Research I Institution, Journal of Chemical Education, 81(3), 2004, pp 441-448.

11. M. Oliver-Hoyo and R. Beichner, SCALE-UP: Bringing Inquiry-Guided Learning to Large Enrollment Courses in Teaching and Learning through Inquiry: A Guidebook for Institutions and Instructors, edited by V. S. Lee, Stylus Publishing, Sterling, VA, 2004, Chapter 5, pp 51-62.

12. S. J. Lea, D. Stephenson, and J. Troy, Higher Education Students' Attitudes to Student Centred Learning: Beyond 'educational bulimia', Studies in Higher Education, 28(3), 2003, pp 321-334.

13. A. Hofstein and V. N. Lunetta, The role of the laboratory in science teaching: Neglected aspects of teaching, Review of Educational Research, 52(2), 1982, pp 201-217.

14. R. Ben-Zvi, A. Hofstein, R. F. Kempa and D. Samuel, The effectiveness of filmed experiments in high school chemical education, Journal of Chemical Education, 53(8), 1976, pp 518-520.

15. SCALE-UPWebsite,

http://scaleup.ncsu.edu/groups/adopters/search/?q=\&sortDirection=forward\&kind=all\&sort=title\&tag=sit e, Accessed March 152010

16. J. A. Wagner III, Studies of Individualism-Collectivism: Effects on Cooperation in Groups, The Academy of Management Journal, 38(1), 1995, pp 152-172.

17. L. S. Kogut, Using Cooperative Learning to Enhance Performance in General Chemistry, Journal of Chemical Education, 74(6), 1997, pp 720-722

18. M. M. Cooper, C. T. Cox, M. Nammouz, R. Stevens and E. Case, An Assessment of the Effect of Collaborative Groups on Students' Problem-Solving Strategies and Abilities, Journal of Chemical Education, 85(6), 2008, pp 866

19. M. M. Cooper, Cooperative Chemistry Laboratories, Journal of Chemical Education, 71(4), 1994, pp 307

20. R. Beichner, J. M. Saul, D. S. Abbott, J. Morse, D. Deardorff, R. J. Allain, S. W. Bonham, M. Dancy and J. Risley, Student-Centered Activities for Large Enrollment Undergraduate Programs (SCALE-UP) project in Research-Based Reform of University Physics, American Association of Physics Teachers, College Park, MD, 2007

21. R. M. Felder and R. Brent, Cooperative Learning in Technical Courses: Procedures, Pitfalls, and Payoffs, ERIC Document Reproduction Service, Ed 377038, October 1994

22. SCALE-UP Website: http://scaleup.ncsu.edu, Accessed March 15, 2010

23. C. Horton, Student Preconceptions and Misconceptions in Chemistry, Integrated Physics and Chemistry Modeling Workshop, (Version 1) Arizona State University, June 2001 
24. M. T. Oliver-Hoyo and D. Allen, The Use of Triangulation Methods to Validate Results of Qualitative Educational Research, Journal of College Science Teaching, 1, 2006, pp 42-47

25. M. T. Oliver-Hoyo and D. Allen, Attitudinal Effects of a Student-Centered Active Learning Environment, Journal of Chemical Education, 82(6), 2005, pp 944-949

26. L. J. Rennie and K. F. Punch, The Relationship Between Affect and Achievement in Science, Journal of Research in Science Teaching, 28, 1991, pp 193-203

27. J. Laforgia, The affective domain related to science education and its evaluation, Science Education, 72 , 1988, pp 407-421

28. R. M. Eddy, Chemophobia in the College Classroom: Extent, Sources, and Student Characteristics, Journal of Chemical Education, 77(4), 2000, pp 514-517.

29. J. P. Gutwill-Wise, The Impact of Active and Context-Based Learning in Introductory Chemistry Courses: An Early Evaluation of the Modular Approach, Journal of Chemical Education, 78(5), 2001, pp 684-690.

30. T. Haladyna and J. Shaughnessy, Attitudes toward science: A quantitative synthesis, Science Education, 66, 1982, pp 547-563

31. B. J. Fraser, Science Teacher Characteristics and Student Attitudinal Outcomes, School Science and Mathematics, 80, 1980, pp 300-308.

32. M. M. Mark and R. L. Shotland, Multiple methods in program evaluation. New directions for program evaluation. 35(2,4,6), San Francisco: Jossey-Bass, 1987

33. W. Wiersma, Research Methods in Education: An introduction, Pearson Education Company, MA, USA, 2000, Chapter 7, pp 157-197

34. R. M. Felder and R. Brent, Navigating the bumpy road to student-centered instruction, College Teaching, 44(2), 1996, pp 43-48. 